\title{
Low CD1c + myeloid dendritic cell counts correlated with a high risk of rapid disease progression during early HIV-1 infection
}

Yingying Diao', Wenqing Geng ${ }^{2,3}$, Xuejie Fan ${ }^{2,3}$, Hualu Cui ${ }^{2,3}$, Hong Sun ${ }^{2,3}$, Yongjun Jiang ${ }^{2,3}$, Yanan Wang ${ }^{2,3}$, Amy Sun ${ }^{2,3}$ and Hong Shang ${ }^{2,3^{*}}$

\begin{abstract}
Background: During early HIV-1 infection (EHI), the interaction between the immune response and the virus determines disease progression. Although CD1c + myeloid dendritic cells (mDCs) can trigger the immune response, the relationship between $\mathrm{CD1c}+\mathrm{mDC}$ alteration and disease progression has not yet been defined.

Methods: EHI changes in CD1C + mDC counts, surface marker (CD40, CD86, CD83) expression, and IL-12 secretion were assessed by flow cytometry in 29 patients.

Results: When compared with the normal controls, patients with EHI displayed significantly lower CD1c + mDC counts and IL-12 secretion and increased surface markers. CD1 + mDC counts were positively correlated with CD4+ T cell counts and inversely associated with viral loads. IL-12 secretion was only positively associated with CD4+ T cell counts. Rapid progressors had lower counts, CD86 expression, and IL-12 secretion of CD1c + mDCs comparing with typical progressors. Kaplan-Meier analysis and Cox regression models suggested patients with low CD1c + mDC counts $(<10$ cells/ $\mu \mathrm{L}$ ) had a 4 -fold higher risk of rapid disease progression than those with high CD1c + mDC counts. However, no relationship was found between surface markers or IL-12 secretion and disease progression.
\end{abstract}

Conclusions: During EHI, patients with low CD1c + mDC counts were more likely to experience rapid disease progression than those with high $C D 1 c+m D C$ counts.

\section{Background}

Myeloid dendritic cells (mDCs) are a subset of dendritic cells (DCs) responsible for presenting antigens. They play critical roles in the induction of innate and acquired immune responses to viruses [1-4]. mDCs consist of heterogeneous cell populations, including the main subpopulation $\mathrm{CD} 1 \mathrm{c}+\mathrm{mDCs}[5,6]$. $\mathrm{CD} 1 \mathrm{c}+\mathrm{mDCs}$ are defined as lineage-negative (including CD3, CD14, CD16, CD19, CD20, and CD56), HLA-DR-positive, and CD1c + CD11c + cells. As one subset of mDCs, CD1c + mDCs can be stimulated by various pathogens (such as HIV-1), which results in the increase of major histocompatibility

\footnotetext{
* Correspondence: hongshang100@hotmail.com

${ }^{2}$ Department of Laboratory Medicine, Key Laboratory of AIDS Immunology of National Health and Family Planning Commission, The First Affiliated

Hospital, China Medical University, Shenyang, Liaoning Province, China

${ }^{3}$ Collaborative Innovation Center for Diagnosis and Treatment of Infectious

Diseases, Hangzhou, Zhejiang Province, China

Full list of author information is available at the end of the article
}

complex (MHC) molecules and surface markers (CD40, CD86, CD83) $[7,8]$, and secretion of large amounts of IL12. Such changes direct Th1 cell development and potently prime cytotoxic lymphocyte (CTLs) [3]. If CD1c+ mDC stimulation is suppressed, HIV-1 infection will progress to AIDS rapidly [9].

Evaluation of HIV-1 disease progression is important to identify early risk factors of disease progression and improve clinical management. HIV-1 typical progressors (TPs) take 8 to 10 years generally to progress to AIDS without antiretroviral therapy [10]. Rapid progressors (RPs), however, progress to AIDS quicker or meet the criteria for initiation of antiretroviral treatment within the first year after seroconversion $[10,11]$. The pathogenesis of HIV-infected patients with rapid progression remains unclear. Early HIV-1 infection (EHI) occurs within the first few months of HIV-1 infection typically; during EHI, HIV-specific immune responses particularly CD8+ T cells affect disease progression [12-17]. CD1c + 
mDCs initiate and modulate immune responses [18], which can induce HIV-1-specific CD8+ T cells to produce type I interferons and slow down disease progression in HIV-1 elite controllers [19]. Previous studies have shown that $\mathrm{CD} 1 \mathrm{c}+\mathrm{mDCs}$ were reduced markedly in number during EHI, and HIV-exposed CD1c + mDCs were not fully activated and showed defective IL-12 production [20]. The relationship between $\mathrm{CD} 1 \mathrm{c}+\mathrm{mDC}$ alteration in EHI and HIV-1 disease progression is unknown. However, the loss of mDCs in early simian immunodeficiency virus (SIV) infection seems to accelerate disease progression [21]. Therefore, we decided to focus on the relationship between $\mathrm{CD} 1 \mathrm{c}+\mathrm{mDC}$ alteration during EHI and disease progression.

In this study, we sought to determine whether $\mathrm{CD} 1 \mathrm{c}+\mathrm{mDC}$ alteration was consistent with $\mathrm{CD} 4+\mathrm{T}$ cell counts or viral loads, whether $\mathrm{CD} 1 \mathrm{c}+\mathrm{mDC}$ alteration was evident in RPs compared with TPs, and whether $\mathrm{CD} 1 \mathrm{c}+\mathrm{mDC}$ alteration was associated with rapid disease progression.

\section{Methods \\ Subjects}

Twenty-nine HIV-1 infected patients with EHI from a cohort of men who have sex with men (MSMs) were recruited for this study $[10,22]$. All patients met the criteria for "early HIV-1 infection" (Fiebig stage V-VI [23]). Beginning in May 2009, all subjects enrolled had their viral loads and CD4+ T cell counts measured at study entry (baseline), at week 1, 2, 3, 7, 11, and 23, and once every 3 months follow-ups starting from week 23, and trial endpoint is January 2013. CD1c+ mDC counts measurement was performed at baseline. RPs were defined as HIV-1 infected individuals who had CD4+ T cell counts $<350$ cells $/ \mu \mathrm{L}$ within the first year of infection $[10,11]$. TPs were subjects whose CD4+ T cell counts remained $\geq 500$ cells $/ \mu \mathrm{L}$ at the 12 -month follow-up visit [10]. Eleven subjects consented to collect large numbers of peripheral blood mononuclear cells (PBMCs) for a more extensive analysis on expression of surface markers and IL- 12 secretion by CD1c + mDCs. 11 normal controls (NCs) were age-matched, healthy, HIV-1 negative individuals. None of the study subjects had syphilis or was infected with hepatitis B or C virus. The study protocol and informed consent forms were approved by Ethical Review Board of the First Affiliated Hospital of China Medical University. Informed consents were obtained from all study subjects.

\section{Counting $\mathrm{CD} 1 \mathrm{c}+\mathrm{mDCs}$}

$\mathrm{CD} 1 \mathrm{c}+\mathrm{mDC}$ counts were monitored with a singleplatform TruCOUNT assay [24]. A total of $100 \mu \mathrm{L}$ anticoagulated whole blood was incubated with the following antibodies for $15 \mathrm{~min}$ in the dark at room temperature: lineage (CD3/CD14/CD16/CD19/CD20/ CD56)-FITC (all antibodies from BD Bioscience, San Jose, CA, unless otherwise noted), CD45-PerCP, HLA-DR-APC/CY7, and CD1c-PE (Biolegend, San Diego, CA). Each tube receiving $450 \mu \mathrm{l}$ of FACS Lysing Solution was vortexed gently, and incubated for another $15 \mathrm{~min}$ in the dark at room temperature. At least 200,000 events were collected from each sample with BD FACS Calibur, and the data obtained were analyzed with CellQuest.

\section{Expression of surface markers}

Frozen PBMCs were thawed rapidly, washed, and then exposed to antibodies against lineage markers CD3PerCP/CY5.5, CD19-PerCP/CY5.5, CD14-PerCP/CY5.5 (Biolegend, San Diego, CA), CD16-PerCP/CY5.5 (Biolegend, San Diego, CA), CD56-PerCP/CY5.5 (Biolegend, San Diego, CA), HLA-DR-APC/CY7, CD11c-PE/CY7 (eBioscience, San Diego, CA), CD1c-PE (Biolegend, San Diego, CA), CD40-FITC, CD86-APC, and CD83-APC. PBMCs were incubated for $30 \mathrm{~min}$ in the dark at $4{ }^{\circ} \mathrm{C}$. Then, the samples were washed and fixed with $1 \%$ paraformaldehyde. At least 200,000 events were collected from each sample with BD FACS LSRII (BD Biosciences, San Diego, CA), and the data obtained were analyzed with FlowJo (Treestar, Ashland, OR).

\section{Cytokine IL-12 Secretion Assays}

Frozen PBMCs were thawed rapidly, washed, and then stimulated with $10 \mu \mathrm{M}$ R848 (Invitrogen, Carlsbad, CA) for $22 \mathrm{~h}$ [25]. Brefeldin A was added $10 \mathrm{~h}$ prior to the end of the incubation period. PBMCs were exposed to antibodies against lineage markers CD3-PerCP/CY5.5, CD19-PerCP/CY5.5, CD14-PerCP/CY5.5 (Biolegend, San Diego, CA), CD16-PerCP/CY5.5 (Biolegend, San Diego, CA), CD56-PerCP/CY5.5 (Biolegend, San Diego, CA), HLA-DR-APC/CY7, CD11c-PE/CY7 (eBioscience, San Diego, CA), CD1c-PE (Biolegend, San Diego, CA) for $30 \mathrm{~min}$ in the dark at $4{ }^{\circ} \mathrm{C}$. Each tube receiving $250 \mu \mathrm{L}$ of Cytofix/Cytoperm solution was vortexed gently, and incubated for $20 \mathrm{~min}$ in the dark at $4{ }^{\circ} \mathrm{C}$. The samples were then washed, exposed to antibodies against IL-12, incubated for $30 \mathrm{~min}$ in the dark at $4{ }^{\circ} \mathrm{C}$, and fixed with $1 \%$ paraformaldehyde. At least 200,000 events were collected from each sample with BD FACS LSRII, and the data obtained were analyzed with FlowJo.

\section{Statistical analysis}

Questionnaires were entered twice, and then checked for accuracy with EpiData software (the EpiData Association, Odense, Denmark, version 3.02). Data were analyzed with SPSS 17.0 software. Categorical data were described, and analyzed by frequency and a chi-square test. An independent $t$ test was used to analyze normally distributed continuous variables between the two groups. 
The Mann-Whitney $U$ test was used for analyzing nonnormally distributed continuous variables. $\mathrm{P}$ values less than 0.05 were considered as statistically significant. For the association between baseline covariates and the primary end point $(\mathrm{CD} 4+\mathrm{T}$ cell count $<350$ cells $/ \mu \mathrm{L}$ or the commencement of ART), Kaplan-Meier plots and Cox regression models were constructed, and subsequently adjusted for baseline covariates.

\section{Results}

\section{The baseline characteristics of HIV-1 infected subjects} with EHI

Baseline characteristics of $29 \mathrm{EHI}$ individuals were described briefly in Table 1. Eighteen subjects (CD4+ T cell counts $<350$ cells $/ \mu \mathrm{L}$ ) were classified as rapid progressors (RPs), whereas 11 subjects $(\mathrm{CD} 4+\mathrm{T}$ cell counts remained $\geq 500$ cells $/ \mu \mathrm{L}$ ) belonged to typical progressors (TPs). In this study, none of the subjects has received ART until after the end of the follow-up. CD4+ T cell counts of RPs decreased rapidly at a rate of 46 cells $/ \mu \mathrm{L} /$ year, before patients (RPs) received ART after infection for 2 years. By the time patients (RPs) received ART, $\mathrm{CD} 4+\mathrm{T}$ cell counts had already decreased to a median of 92 cells $/ \mu \mathrm{L}$ by comparing with those during baseline $(p=0.007)$. Viral loads of RPs increased at a rate of $0.219 \log _{10}$ copies $/ \mathrm{mL} /$ year over 2 years after infection. When patients (RPs) received ART, viral loads slightly increased by comparing with those during baseline. However, CD4+ T cell counts in TPs decreased slowly at a rate of 33 cells $/ \mu \mathrm{L} /$ year, before patients (TPs) received
ART after 3 years of infection. When patients (TPs) received ART, CD4+ T cell counts decreased to a median of 99 cells $/ \mu \mathrm{L}$ by comparing with those during baseline $(p=0.007)$. Viral loads of TPs increased at a rate of $0.110 \log _{10}$ copies $/ \mathrm{mL} /$ year over 3 years after infection. When patients (TPs) received ART, viral loads slightly increased by comparing with those during baseline. There were no obvious changes in CD4+ T cell percentages over time in RPs or TPs. After RPs received ART for approximately 1 year, viral loads decreased significantly $(p=0.019)$, but there were no significant changes in CD4+ $\mathrm{T}$ cell counts or CD4+ $\mathrm{T}$ cell percentages. There were no obvious changes in TPs; however, the ART observation time was very short.

The main HIV-1 subtype among the individuals was HIV_AE. The patients had a median viral load of 4.70 (3.78-5.50) $\log _{10}$ copies/mL, and an median CD4+ T cell count of $490(312-568)$ cells/ $\mu \mathrm{L}$. CD4+ T cell counts in EHI subjects were significantly lower than those in NCs $(p=0.015)$ (Table 1).

The data of baseline demographic characteristics (age, race, gender) and the follow-up durations were comparable between RPs and TPs. At baseline, CD4+ T cell counts in RPs were significantly lower than those in TPs $(p<0.001)$, but viral load levels were similar (Table 1$)$.

\section{CD1c + mDC counts and IL-12 secretion in EHI subjects} were associated with markers of disease progression

To assess whether changes in $\mathrm{CD} 1 \mathrm{c}+\mathrm{mDC}$ counts, surface marker expression, and IL-12 secretion would be

Table 1 Clinical and epidemiological characteristics of seronegative individuals, EHI patients, RPs, and TPS

\begin{tabular}{|c|c|c|c|c|c|}
\hline & $N C s N=11$ & $\mathrm{EHI} N=29$ & $\operatorname{RPs} N=18$ & TPs $N=11$ & $P\left(P^{a} / P^{b}\right)$ \\
\hline Age, years & $31(28-35)$ & $28(22-39)$ & $37(23-42)$ & $25(22-35)$ & NS/NS \\
\hline Han ethnicity, no., (\%) & $11(100 \%)$ & $29(100 \%)$ & $18(100 \%)$ & $11(100 \%)$ & NS/NS \\
\hline Male gender, no., (\%) & $11(100 \%)$ & $29(100 \%)$ & $18(100 \%)$ & $11(100 \%)$ & NS/NS \\
\hline Follow-up days, days & NA & $1149(862-1297)$ & $1091(821-1311)$ & $1171(990-1284)$ & NA/NS \\
\hline \multicolumn{6}{|l|}{ At baseline } \\
\hline Estimated time at baseline, days & NA & $55(36-100)$ & $69(35-102)$ & $53(37-81)$ & NA/NS \\
\hline Baseline CD4 + T cell counts, cells/ $/ \mathrm{L}$ & $728(568-876)$ & $490(312-568)$ & $337(265-520)$ & $586(499-685)$ & $0.015 / 0.000$ \\
\hline Baseline HIV-1 RNA load, $\log _{10}$ copies $/ \mathrm{mL}$ & NA & $4.70(3.78-5.50)$ & $5.02(4.24-5.78)$ & $4.03(3.06-5.15)$ & NA/NS \\
\hline \multicolumn{6}{|l|}{ At 12-month follow-up visit } \\
\hline CD4 + T cell counts, cells $/ \mu \mathrm{L}$ & NA & $329(271-539)$ & $298(239-328)$ & $599(525-732)$ & NA/0.000 \\
\hline HIV-1 RNA load, $\log _{10}$ copies/mL & NA & $4.50(3.64-4.85)$ & $4.55(3.19-4.85)$ & $4.45(3.73-4.91)$ & NA/0.902 \\
\hline \multicolumn{6}{|l|}{ At primary endpoint } \\
\hline Estimated time at primary endpoint, days & NA & $340(104-1149)$ & $123(79-272)$ & $1171(990-1284)$ & NA/0.000 \\
\hline CD4 + T cell counts, cells/uL & NA & $321(281-467)$ & $311(274-342)$ & $422(309-541)$ & NA/0.027 \\
\hline HIV-1 RNA load, $\log _{10}$ copies/mL & NA & $4.59(3.89-5.27)$ & $4.59(3.79-4.71)$ & $4.49(3.88-5.37)$ & NA/0.152 \\
\hline
\end{tabular}

Data are values (\% of nonmissing values) for categorical variables and medians (interquartile range) for continuous variables

NCS normal controls, EHI subjects with early HIV-1 infection, RPs rapid progressors, TPs typical progressors, NA not applicable, NS not significant $P$-value from independent $t$ test for normally distributed continuous variables or Mann-Whitney $U$ test for non-normally distributed continuous variables. $\mathrm{P}^{\mathrm{a}}$ comparisons between NCs and EHI, $\mathrm{P}^{\mathrm{b}}$ comparisons between RPs and TPs 
evident during EHI, we found that patients with EHI had significantly lower CD1c + mDC counts and IL-12 secretion levels compared with NCs $(p=0.018$, $p=0.010$ ) (Fig. 1a and c). CD1c $+\mathrm{mDC}$ had significantly higher expression of CD86, CD40, and CD83 during EHI compared with $\mathrm{CD} 1 \mathrm{c}+\mathrm{mDC}$ of $\mathrm{NCs}(p=0.001$, $p=0.037$, and $p<0.001$, respectively) (Fig. 1b).

Next, we evaluated whether viral loads and CD4+ T cell counts, the only validated markers of progression used in HIV-1 clinic [26, 27], were correlated with CD1c + $\mathrm{mDC}$ counts or IL-12 secretion. CD1c + mDC counts were positively associated with $\mathrm{CD} 4+\mathrm{T}$ cell counts $(r=0.572, p=0.001)$, and inversely associated with viral loads $(r=-0.418, p=0.024)$ (Fig. 1a). However, IL-12 secretion was only positively associated with CD4+ T cell counts $(r=0.606, p=0.048)$, but not with viral loads $(r=-0.461, p=0.154)$ (Fig. 1c). There was no relationship between surface molecule expression and CD4+ $\mathrm{T}$ cell counts or viral loads (data not shown).

\section{CD1c + mDC counts and IL-12 secretion level were lower} in RPs

Since the disease in RPs progressed more rapidly, we next determined whether abnormally low $\mathrm{CD} 1 \mathrm{c}+\mathrm{mDC}$ counts and expression of CD40, CD86, and CD83, and IL-12 secretion would be evident in RPs. CD1c + mDC counts in RPs were significantly lower than those in TPs $(p=0.018)$ (Fig. 2a, 2b, 2c). In addition to CD40 and CD83, RPs also had lower CD86 expression than TPs $(p=0.045)$ (Fig. 2a, 2b, 2d). CD1c $+\mathrm{mDC}$ secretion of IL-12 in RPs was also significantly lower than TPs stimulated with R848 ( $p=0.004$ ) (Fig. 2a, 2b, 2e).

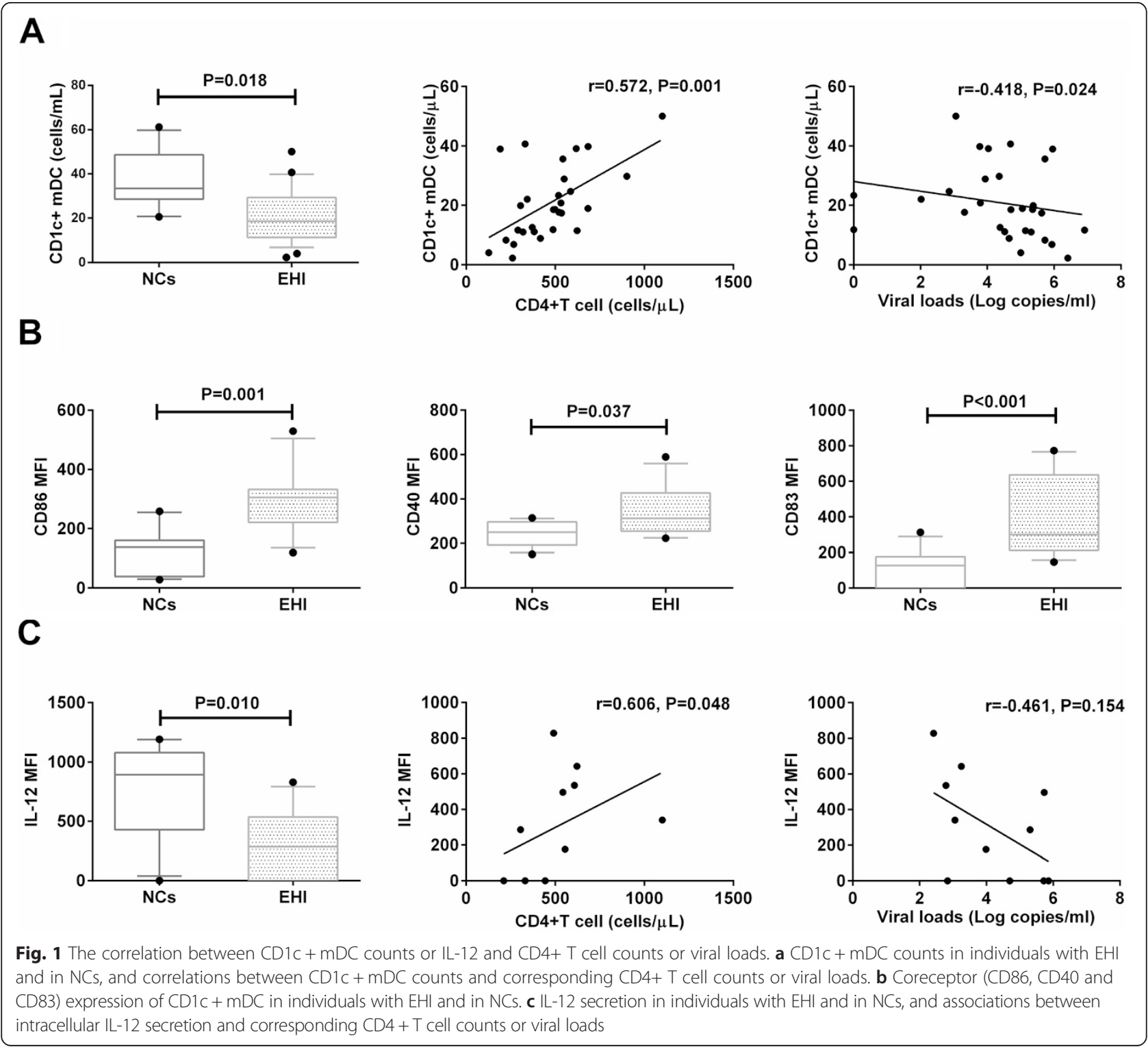




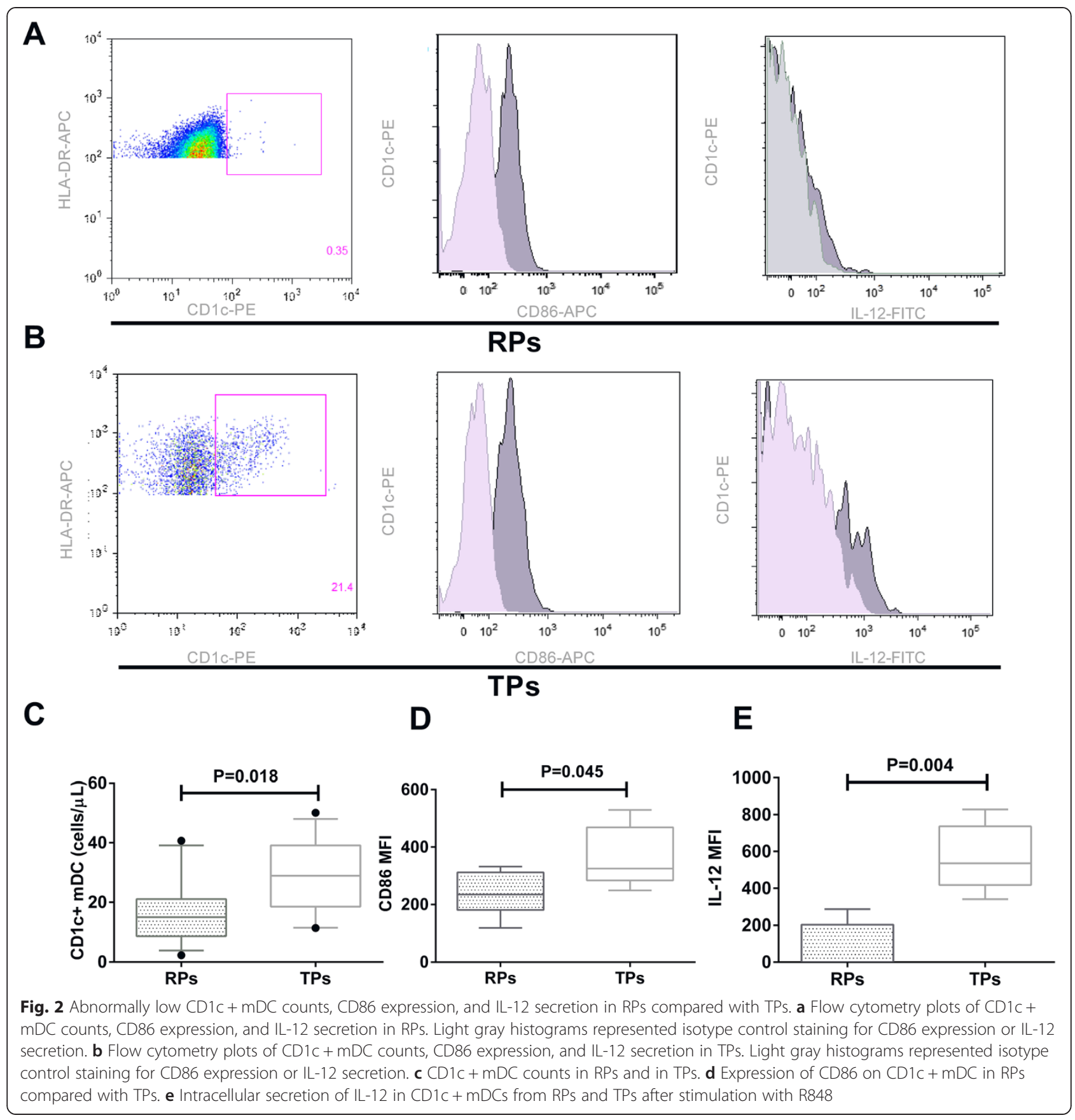

\section{Association between $\mathrm{CD} 1 \mathrm{c}+\mathrm{mDC}$ counts in EHI subjects and disease progression}

Disease progression was defined according to the primary endpoint of the CD4+ T cell count of 350 cells $/ \mu \mathrm{L}$ or the commencement of ART. All patients received ART at the trail endpoint. We carried out Kaplan-Meier survival analyses, and stratified according to CD1c $+\mathrm{mDC}$ counts $(<10$ cells $/ \mu \mathrm{L}$ or $\geq 10$ cells $/ \mu \mathrm{L})$ or median IL-12 level at baseline. There was a significant acceleration in clinical progression in those with lower $\mathrm{CD} 1 \mathrm{c}+\mathrm{mDC}$ counts $(\log \operatorname{rank} \times 2=13.63, p<0.001$ ) (Fig. 3a) or IL-12 level (log rank $\times 2=4.10, p=0.043$ ) (Fig. 3b). The median time from baseline to primary endpoint for low and high CD1c + mDC counts was 95.0 (IQR 52.0-211.5) and 821.0 (IQR 248.5-1,170.5) days, respectively; for low and high IL-12 levels, it was 77.0 (IQR 36.0-183.8) and 1,101.0 (IQR 400.0-1481.0) days, respectively (Fig. 3).

Univariable cox analyses showed low CD1c $+\mathrm{mDC}$ counts $[H R=6.52(2.11-20.14) ; p=0.001]$, low IL-12 level $[H R=8.83(1.01-77.29) ; p=0.049]$, and low CD4+ $\mathrm{T}$ cell counts $(\leq 350$ cells $/ \mu \mathrm{L}) \quad[H R=0.34 \quad(0.14-0.82)$; $p=0.016]$, which predicted time to primary endpoint 


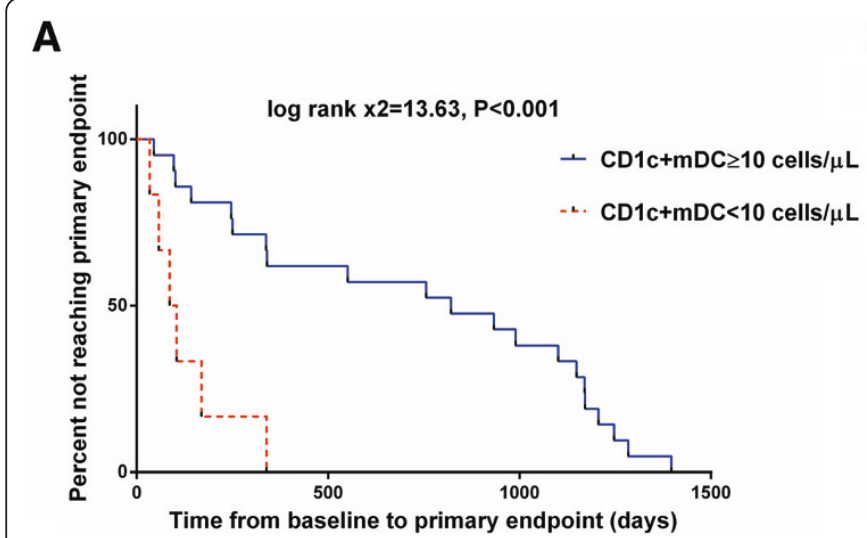

B

Fig. 3 Time from baseline to CD4+ T cell count of less than 350 cells/ $\mu \mathrm{L}$ or commencement of ART. a Kaplan-Meier survival plots for survival time

of low and high CD1c $+\mathrm{mDC}$ count groups. b Kaplan-Meier survival plots for survival time of low and high IL-12 secretion groups

(Table 2). Multivariable analyses were carried out with the baseline covariates, $\mathrm{CD} 1 \mathrm{c}+\mathrm{mDC}$ counts, viral loads, and $\mathrm{CD} 4+\mathrm{T}$ cell counts. Low $\mathrm{CD} 1 \mathrm{c}+\mathrm{mDC}$ counts $[4.76$ (1.40-16.18); $p=0.012]$ but not low CD4+ counts $[H R=$ $0.39(0.11-1.37) ; p=0.140]$ or high viral loads $\left(>5 \log _{10}\right.$ copies $/ \mathrm{mL})[H R=0.55(0.14-2.10) ; p=0.383]$ predicted time to primary endpoint (Table 2). In a parallel multivariable analysis, low IL-12 level was not significantly associated with the trial endpoint.

\section{Discussion}

Early plasmacytoid dendritic cell changes predict plasma HIV load rebound during primary infection [28], but the specific role of mDCs during early HIV-1 infection remains poorly defined. Previous data from macaques revealed that the loss of mDCs during early SIV infection was predictive of disease progression. Therefore, the goal of this study was to explore the correlation between $\mathrm{CD} 1 \mathrm{c}+\mathrm{mDC}$ alteration in patients with $\mathrm{EHI}$ and disease progression. We found $\mathrm{CD} 1 \mathrm{c}+\mathrm{mDC}$ counts and IL-12 secretion were positively associated with $\mathrm{CD} 4+\mathrm{T}$ cell counts, and $\mathrm{CD} 1 \mathrm{c}+\mathrm{mDC}$ counts were inversely associated with viral loads. Furthermore, CD1c $+\mathrm{mDC}$ counts and IL-12 secretion level in RPs decreased comparing with those in TPs. Finally, low CD1c $+\mathrm{mDC}$ counts $(<10$ cells $/ \mu \mathrm{L})$ were associated with an increased

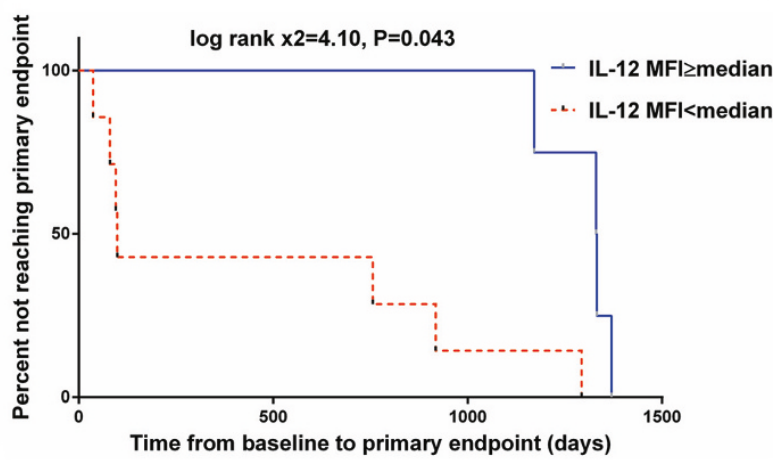

risk of more rapid disease progression, suggesting a possible target for intervention.

While CD1c + mDC counts and IL-12 secretion decreased, the expression of several surface molecules (CD40, CD86, CD83) increased during EHI. The results were consistent with the previous studies that have demonstrated IL-12 secretion defects in mDCs, CD86 and CD83 up-regulation on monocyte-derived dendritic cells (MDDCs) [9, 10, 29-33]. However, in contrast to our results, a previous study found that mDCs of patients with EHI produced significantly higher levels of IL-12 than normal controls [34]. It might be due to the presence or absence of the circulating immunomodulatory environment within the in vitro culture system [34]. The influence of the extracellular milieu or apoptotic microparticles, derived from dying cells during acute HIV-1 infection, has been shown to suppress $\mathrm{mDC}$ function $[28,29,35]$.

To our knowledge, no previous study has found that changes in mDCs correlated with either $\mathrm{CD} 4+\mathrm{T}$ cell counts or viral loads during EHI $[10,31]$. Our results revealed that it might be due to the heterogeneity of $\mathrm{mDCs}$. CD1c $+\mathrm{mDCs}$, one dominant subset of $\mathrm{mDCs}$, were most closely related to $\mathrm{CD} 4+\mathrm{T}$ cell counts and HIV-1 viral loads during EHI. Patients with greater $\mathrm{CD} 1 \mathrm{c}+\mathrm{mDC}$ counts and IL-12 secretion had higher CD4+ $\mathrm{T}$ cell counts and patients with greater CD1c +

Table 2 Association between primary endpoint (CD4+ T cell count <350 cells/ml or commencement of long-term ART) and baseline characteristics

\begin{tabular}{|c|c|c|c|c|}
\hline \multirow[b]{2}{*}{ Covariate } & \multicolumn{2}{|c|}{ Univariable unadjusted } & \multicolumn{2}{|c|}{ Multivariable adjusted $^{a}$} \\
\hline & HR (95 \% Cl) & $\mathrm{P}^{\mathrm{a}}$ & $\mathrm{HR}(95 \% \mathrm{Cl})$ & $\mathrm{P}^{\mathrm{b}}$ \\
\hline $\mathrm{CD} 1 \mathrm{c}+\mathrm{mDC}$ count $(<10$ versus $\geq 10$ cells $/ \mu \mathrm{L})$ & $6.52(2.11-20.14)$ & 0.001 & $4.76(1.40-16.18)$ & 0.012 \\
\hline CD4+ T cell count ( $<350$ versus $\geq 350$ cells $/ \mu \mathrm{L}$ ) & $0.34(0.14-0.82)$ & 0.016 & $0.39(0.11-1.37)$ & 0.140 \\
\hline Viral load $(<5$ versus $\geq 5 \log 10$ copies $/ \mathrm{mL}$ ) & $1.50(0.67-3.36)$ & 0.320 & $0.55(0.14-2.10)$ & 0.383 \\
\hline
\end{tabular}

$C l$ confidence interval, $H R$ hazard ratio. $P$-value from Wald test

$P^{a}$-value is from univariable cox analyses. $P^{b}$-value is from multivariable cox analyses

${ }^{a}$ Results adjusted for CD1c + mDC counts, CD4+ T cell counts, and HIV viral loads 
mDC counts had lower viral loads. However, there was no correlation between the expression of several surface markers (CD40, CD86, CD83) and CD4+ T cell counts or viral loads.

Our results also showed that $\mathrm{CD} 1 \mathrm{c}+\mathrm{mDC}$ counts, CD86 expression, and IL-12 secretion were significantly lower in RPs during EHI. Other studies have found similar results for $\mathrm{mDCs}$ and $\mathrm{CD} 11 \mathrm{c}+\mathrm{CD} 16-\mathrm{mDCs}$ $[10,36]$. Thus, increased CD1c $+\mathrm{mDC}$ counts, CD86 expression, and IL-12 secretion seemed to be associated with slower disease progression. The decrease in CD1c $+\mathrm{mDC}$ counts observed in HIV-1-infected individuals could be due to HIV-1-induced cell death or recruitment to lymphoid organs [36]. While the underlying cause of the faster decline of CD1c + mDC counts in RPs was unclear, the virus might induce more cell death or recruit more $\mathrm{CD} 1 \mathrm{c}+\mathrm{mDCs}$ to lymphoid organs. However, less IL-12 secretion in RPs could be due to a lower CD1c + $\mathrm{mDC}$ count or a dysfunction induced by HIV-1. Interestingly, we found that CD86 expression was higher in patients with EHI than that in normal controls, which implied that $\mathrm{CD} 1 \mathrm{c}+\mathrm{mDCs}$ were activated by the virus. However, CD86 expression on CD1c + mDCs was reduced in RPs by comparing with that in TPs, indicated that the virus might inactivate $\mathrm{CD} 1 \mathrm{c}+\mathrm{mDCs}$. Although the mechanism was unknown, the decline of CD86 expression has been shown to inhibit $\mathrm{CD} 1 \mathrm{c}+\mathrm{mDC}$ maturation and suppress immune response [36].

Low $\mathrm{CD} 1 \mathrm{c}+\mathrm{mDC}$ counts $(<10$ cells $/ \mu \mathrm{L})$ were associated with an increased risk of more rapid disease progression. The patients with low $\mathrm{CD} 1 \mathrm{c}+\mathrm{mDC}$ counts had 4-fold higher odds of rapid disease progression than those with high $\mathrm{CD} 1 \mathrm{c}+\mathrm{mDC}$ counts. It could be due to several different mechanisms. Firstly, CD1c + mDCs had cytotoxic properties [37], so the decrease in $\mathrm{CD} 1 \mathrm{c}+$ mDCs might compromise the ability of the immune system to kill virus-infected cells. Secondly, HIV-1 infected $\mathrm{CD} 1 \mathrm{c}+\mathrm{mDCs}$ selectively in human blood. The infected $\mathrm{CD} 1 \mathrm{c}+\mathrm{mDCs}$ mobilized from the blood to the lymph nodes, and then underwent apoptosis [21]. The decline of $\mathrm{CD} 1 \mathrm{c}+\mathrm{mDCs}$ would weaken the immune response. Thirdly, downregulation of CD1c molecules by HIV-1 infection weakened the ability of CD1c-restricted T cells to respond to and secrete interferon- $\gamma$ [38]. We did not find that IL-12 secretion level was predictive of disease progression. However, IL-12 could promote resistance to HIV infection [39], and a previous study has showed that plasma IL-12 levels during acute HIV-1 infection predicted HIV disease progression [40]. Further studies are needed to clarify the impact of IL-12 secreted by CD1c + mDCs on disease development.

Although our results did not reveal whether TP and RP patients would benefit from early ART, they did suggest that a low $\mathrm{CD} 1 \mathrm{c}+\mathrm{mDC}$ count $(<10$ cells $/ \mu \mathrm{L})$ provided important prognostic information which could be used to guide therapy. Since patients with a low $\mathrm{CD} 1 \mathrm{c}+\mathrm{mDC}$ count are more at risk for rapid disease progression without therapy, such patients may be more likely to benefit from early treatment.

\section{Conclusions}

In conclusion, $\mathrm{CD} 1 \mathrm{c}+\mathrm{mDC}$ counts and IL-12 secretion were positively associated with $\mathrm{CD} 4+\mathrm{T}$ cell counts, and $\mathrm{CD} 1 \mathrm{c}+\mathrm{mDC}$ counts were inversely associated with viral loads. CD1c + mDC counts, CD86 expression, and IL-12 secretion level in RPs were lower than those in TPs. Low $\mathrm{CD} 1 \mathrm{c}+\mathrm{mDC}$ counts were correlated with a high risk of rapid disease progression during EHI, suggesting a potentially important prognostic marker and a promising target for intervention.

\section{Competing interests}

The authors declare that they have no competing interests.

\section{Authors' contributions}

HS had given final approval of the version to be published and agreed to be accountable for all aspects of the work in ensuring that questions related to the accuracy or integrity of any part of the work are appropriately investigated and resolved. She reviewed all the manuscript. YD had made substantial contributions to conception and design, or acquisition of data, or analysis and interpretation of data. WG corresponded with conception and design and writing. XF performed acquisition of data. YJ and YW provided support for correspondence with the experts and advisory groups. AS carried out a part of the data collection and provided with many valuable writing instructions and helped to draft the manuscript. All authors have critically reviewed and approved the final manuscript.

\section{Acknowledgements}

We would like to thank Bin Zhao and BioMed Proofreading, LLC for useful advices on our writing. We also thank Min Zhao provided funds for our study. This work was supported by grants through: National Natural Science Foundation of China (no. 81102231), National Natural Science Foundation of China (no. 81273238), Mega-projects of National Science Research for the 12th 5-Year Plan (2012ZX10001-006), Development Plan of Innovative Group of Misnistry of Education 2012, National Natural Science Foundation of China (no. 81201345).

\section{Author details}

${ }^{1}$ Department of Laboratory Medicine, The First Affiliated Hospital, China Medical University, Shenyang, Liaoning Province, China. ²Department of Laboratory Medicine, Key Laboratory of AIDS Immunology of National Health and Family Planning Commission, The First Affiliated Hospital, China Medical University, Shenyang, Liaoning Province, China. ${ }^{3}$ Collaborative Innovation Center for Diagnosis and Treatment of Infectious Diseases, Hangzhou, Zhejiang Province, China.

Received: 9 April 2015 Accepted: 5 August 2015

Published online: 19 August 2015

\section{References}

1. Henriques A, Ines L, Carvalheiro T, Couto M, Andrade A, Pedreiro S, et al. Functional characterization of peripheral blood dendritic cells and monocytes in systemic lupus erythematosus. Rheumatol Int. 2011;32(4):863-9.

2. MacDonald KP, Munster DJ, Clark GJ, Dzionek A, Schmitz J, Hart DN. Characterization of human blood dendritic cell subsets. Blood. 2002;100(13):4512-20.

3. Nizzoli G, Krietsch J, Weick A, Steinfelder S, Facciotti F, Gruarin P, et al. Human CD1C + dendritic cells secrete high levels of IL-12 and potently prime cytotoxic T cell responses. Blood. 2013;122(6):932-42. 
4. Mildner A, Jung S. Development and Function of Dendritic Cell Subsets. Immunity. 2014;40(5):642-56.

5. Palucka K, Banchereau J. Cancer immunotherapy via dendritic cells. Nat Rev Cancer. 2012;12(4):265-77.

6. Dzionek A, Fuchs A, Schmidt P, Cremer S, Zysk M, Miltenyi S, et al. BDCA-2, $\mathrm{BDCA}-3$, and BDCA-4: three markers for distinct subsets of dendritic cells in human peripheral blood. J Immunol. 2000;165(11):6037-46.

7. Schacker TW, Hughes JP, Shea T, Coombs RW, Corey L. Biological and virologic characteristics of primary HIV infection. Ann Intern Med. 1998;128(8):613-20.

8. Banchereau J, Briere F, Caux C, Davoust J, Lebecque S, Liu YJ, et al. Immunobiology of dendritic cells. Annu Rev Immunol. 2000;18:767-811.

9. Donaghy H, Gazzard B, Gotch F, Patterson S. Dysfunction and infection of freshly isolated blood myeloid and plasmacytoid dendritic cells in patients infected with HIV-1. Blood. 2003;101(11):4505-11.

10. Geng W, Fan X, Diao Y, Cui H, Sun H, Yun K, et al. Rapid disease progression in HIV-1-infected men who have sex with men is negatively correlated with peripheral plasmacytoid dendritic cell counts at the early stage of primary infection. J Clin Immunol. 2011;31(5):882-90.

11. Dalmau J, Rotger M, Erkizia I, Rauch A, Reche P, Pino M, et al. Highly pathogenic adapted HIV-1 strains limit host immunity and dictate rapid disease progression. AIDS (London, England). 2014;28(9):1261-72.

12. Craib KJ, Strathdee SA, Hogg RS, Leung B, Montaner JS, O'Shaughnessy MV, et al. Serum levels of human immunodeficiency virus type 1 (HIV-1) RNA after seroconversion: a predictor of long-term mortality in HIV infection. J Infect Dis. 1997;176(3):798-800.

13. Katzenstein TL, Pedersen C, Nielsen C, Lundgren JD, Jakobsen PH, Gerstoft J, Longitudinal serum HIV RNA quantification: correlation to viral phenotype at seroconversion and clinical outcome. AIDS (London, England). 1996;10(2):167-73.

14. Musey L, Hughes J, Schacker T, Shea T, Corey L, McElrath MJ. Cytotoxic-T-cell responses, viral load, and disease progression in early human immunodeficiency virus type 1 infection. N Engl J Med. 1997;337(18):1267-74.

15. Schmitz JE, Kuroda MJ, Santra S, Sasseville VG, Simon MA, Lifton MA, et al. Control of viremia in simian immunodeficiency virus infection by CD8+ lymphocytes. Science (New York NY). 1999;283(5403):857-60.

16. Koup RA, Safrit JT, Cao Y, Andrews CA, McLeod G, Borkowsky W, et al. Temporal association of cellular immune responses with the initial control of viremia in primary human immunodeficiency virus type 1 syndrome. J Virol. 1994;68(7):4650-5.

17. Connick E, Marr DG, Zhang XQ, Clark SJ, Saag MS, Schooley RT, et al. HIV-specific cellular and humoral immune responses in primary HIV infection. AIDS Res Hum Retrovir. 1996;12(12):1129-40.

18. Allen RC, Armitage RJ, Conley ME, Rosenblatt H, Jenkins NA, Copeland NG, et al. CD40 ligand gene defects responsible for X-linked hyper-lgM syndrome. Science (New York, NY). 1993;259(5097):990-3.

19. Martin-Gayo E, Buzon MJ, Ouyang Z, Hickman T, Cronin J, Pimenova D, et al. Potent Cell-Intrinsic Immune Responses in Dendritic Cells Facilitate HIV-1Specific T Cell Immunity in HIV-1 Elite Controllers. PLoS Pathog. 2015;11(6):e1004930.

20. Almeida J, Bueno C, Alguero MC, Sanchez ML, de Santiago M, Escribano L, et al. Comparative analysis of the morphological, cytochemical, immunophenotypical, and functional characteristics of normal human peripheral blood lineage(-)/CD16(+)/HLA-DR(+)/CD14(-/lo) cells, CD14(+) monocytes, and CD16(-) dendritic cells. Clinical immunology (Orlando, Fla). 2001;100(3):325-38.

21. Wijewardana V, Soloff AC, Liu X, Brown KN, Barratt-Boyes SM. Early myeloid dendritic cell dysregulation is predictive of disease progression in simian immunodeficiency virus infection. PLoS Pathog. 2010;6(12):e1001235.

22. Shang $H, X u$ J, Han X, Spero Li J, Arledge KC, Zhang L. HIV prevention: Bring safe sex to China. Nature. 2012;485(7400):576-7.

23. Fiebig EW, Wright DJ, Rawal BD, Garrett PE, Schumacher RT, Peddada L, et al. Dynamics of HIV viremia and antibody seroconversion in plasma donors: implications for diagnosis and staging of primary HIV infection. AIDS (London, England). 2003;17(13):1871-9.

24. Vuckovic S, Gardiner D, Field K, Chapman GV, Khalil D, Gill D, et al. Monitoring dendritic cells in clinical practice using a new whole blood single-platform TruCOUNT assay. J Immunol Methods. 2004;284(1-2):73-87.

25. Heil F, Hemmi H, Hochrein H, Ampenberger F, Kirschning C, Akira S, et al. Species-specific recognition of single-stranded RNA via toll-like receptor 7 and 8. Science (New York NY). 2004;303(5663):1526-9.
26. Mellors JW, Rinaldo Jr CR, Gupta P, White RM, Todd JA, Kingsley LA. Prognosis in HIV-1 infection predicted by the quantity of virus in plasma. Science (New York NY). 1996;272(5265):1167-70.

27. Frater J, Ewings F, Hurst J, Brown H, Robinson N, Fidler S, et al. HIV-1-specific $\mathrm{CD} 4(+)$ responses in primary HIV-1 infection predict disease progression. AIDS (London, England). 2014;28(5):699-708.

28. Alter $G$, Altfeld M. Mutiny or scrutiny: NK cell modulation of DC function in HIV-1 infection. Trends Immunol. 2011;32(5):219-24.

29. Frleta D, Ochoa CE, Kramer HB, Khan SA, Stacey AR, Borrow P, et al. HIV-1 infection-induced apoptotic microparticles inhibit human DCs via CD44. J Clin Invest. 2012;122(12):4685-97.

30. Huang J, Yang Y, Al-Mozaini M, Burke PS, Beamon J, Carrington MF, et al. Dendritic cell dysfunction during primary HIV-1 infection. J Infec Dis. 2011;204(10):1557-62.

31. Pacanowski J, Kahi S, Baillet M, Lebon P, Deveau C, Goujard C, et al. Reduced blood CD123+ (lymphoid) and CD11C + (myeloid) dendritic cell numbers in primary HIV-1 infection. Blood. 2001;98(10):3016-21.

32. Granelli-Piperno A, Golebiowska A, Trumpfheller C, Siegal FP, Steinman RM. HIV-1-infected monocyte-derived dendritic cells do not undergo maturation but can elicit IL-10 production and T cell regulation. Proc Natl Acad Sci U S A. 2004;101(20):7669-74.

33. Smed-Sorensen A, Lore K, Walther-Jallow L, Andersson J, Spetz AL. HIV-1infected dendritic cells up-regulate cell surface markers but fail to produce IL-12 p70 in response to CD40 ligand stimulation. Blood. 2004;104(9):2810-7.

34. Sabado RL, O'Brien M, Subedi A, Qin L, Hu N, Taylor E, et al. Evidence of dysregulation of dendritic cells in primary HIV infection. Blood. 2010;116(19):3839-52.

35. Mavilio D, Lombardo G, Kinter A, Fogli M, La Sala A, Ortolano S, et al. Characterization of the defective interaction between a subset of natura killer cells and dendritic cells in HIV-1 infection. J Exp Clin Cancer Res. 2006;203(10):2339-50.

36. Fontaine J, Coutlee F, Tremblay C, Routy JP, Poudrier J, Roger M. HIV infection affects blood myeloid dendritic cells after successful therapy and despite nonprogressing clinical disease. J Infect Dis. 2009;199(7):1007-18.

37. Ciesek S, Liermann H, Hadem J, Greten T, Tillmann HL, Cornberg M, et al. Impaired TRAIL-dependent cytotoxicity of CD1c-positive dendritic cells in chronic hepatitis C virus infection. J Viral Hepat. 2008;15(3):200-11.

38. Kelly H, Mandraju R, Coelho-dos-Reis JG, Tsuji M. Effects of HIV-1-induced CD1C and CD1d modulation and endogenous lipid presentation on CD1Crestricted T-cell activation. BMC Immunol. 2013;14:4

39. Clerici M, Lucey DR, Berzofsky JA, Pinto LA, Wynn TA, Blatt SP, et al. Restoration of HIV-specific cell-mediated immune responses by interleukin-12 in vitro. Science (New York, NY). 1993;262(5140):1721-4.

40. Roberts L, Passmore JA, Williamson C, Little F, Bebell LM, Mlisana K, et al. Plasma cytokine levels during acute HIV-1 infection predict HIV disease progression. AIDS (London, England). 2010;24(6):819-31.

\section{Submit your next manuscript to BioMed Central and take full advantage of:}

- Convenient online submission

- Thorough peer review

- No space constraints or color figure charges

- Immediate publication on acceptance

- Inclusion in PubMed, CAS, Scopus and Google Scholar

- Research which is freely available for redistribution 